\title{
Reductive Views of Shared Intention
}

(To appear in Kirk Ludwig and Marija Jankovic (eds.), The Routledge Handbook of Collective

Intentionality, Routledge, 2017.)

Facundo M. Alonso - Miami University, Ohio

Joint action is pervasive among us. We carry a piano upstairs, dance the tango, paint a house together, go for a walk together, and prepare hollandaise sauce together. Joint action is also something we value or care about -both intrinsically and instrumentally. We enjoy going for a walk together and preparing hollandaise sauce together; and we carry a piano upstairs together and paint a house together because we find it difficult to achieve the intended results on our own. But what is it for us to act together? Philosophers agree that joint action is not simply an aggregation of acts by individuals, however coordinated. People can be acting individually in a coordinated way -acting in parallel, as we might say—but still not be acting jointly in a proper sense. The difference is often illustrated by reference to contrast cases (Tuomela and Miller 1988; Searle 1990; Gilbert 1992, 2000; Bratman 2006, 2014). Consider one suggested by Michael Bratman (2006). Imagine that you and I are walking together down Fifth Avenue. Now contrast this with a case in which I am walking down Fifth Avenue alongside a stranger and in which the stranger and I are walking at the same pace, without bumping into each other. Both cases involve a sequence of individual, coordinated acts. Yet, it is intuitively clear that the case of you and I walking down Fifth Avenue constitutes an instance of joint action, while the case of my walking alongside a stranger does not. It is usually inferred from this that the mark of joint action does not reside solely in its external or behavioral component. It resides also, and more 
fundamentally, in its internal component, in the participants' having a shared (or collective or joint) intention to so act.

We may distinguish between two opposing views of shared intention: reductive views and non-reductive views. For the sake of consistency, here I follow the conceptualization of such a distinction introduced in Chapter 3 above. Reductive views assert that shared intention is best understood in terms of the properties and concepts already available in our understanding of individual intention and action, while non-reductive views deny this. Our concern in this chapter is with the former views. In what follows I consider key aspects of three main reductive views of shared intention: those offered, respectively, by Raimo Tuomela and Kaarlo Miller (1988), ${ }^{\mathrm{i}}$ Michael Bratman (1993; 1997; 2006, 2009, 2014), and Kirk Ludwig (2007b, 2017).

According to Tuomela and Miller, one of the features that distinguishes the intention of a group concerning a group's activity -that is, shared intention-from the intention of an individual concerning his own activity is that only the former involves relevant "we-attitudes" on the part of individuals, that is, attitudes of individuals that make (purported) reference to the other individuals in the group (1988: 367). Among such we-attitudes we find not only cognitive attitudes of individuals, such as (mutual) beliefs about each other's future actions. We find also, and perhaps more importantly, relevant conative attitudes of individuals, such as intentions of individuals (370). Rival approaches to joint action -including game-theoretic approaches-are unsatisfactory, the authors claim, insofar as they fail to acknowledge the relevance of conative "we-attitudes" for shared intention and action (371-72).

In Tuomela and Miller's view, shared intention involves, principally, attitudes of "weintention" on the part of individuals. An individual's we-intention is a complex attitude that includes both conative and cognitive elements. Basically, the authors analyze "we-intention" 
thus: (WI) an individual we-intends to do $X$-where $X$ is the joint activity - if and only if (i) he intends to do his part of $X$ (as his part of $X$ ); (ii) he believes that the other members of the group will do their parts of $X$; and (iii) he believes that there is a mutual belief among the members of the group that each will perform his part of $X$ (1988: 375). (For discussion of the role of mutual belief and of common knowledge in the context of shared agency, see esp. Chant and Ernst [2008] and Blomberg [2016].) Suppose that you and I have a shared intention to prepare hollandaise sauce and that you will contribute to it by pouring in the ingredients and I will contribute by stirring them. It follows from Tuomela and Miller's view that each of us weintends to prepare hollandaise sauce -where my so we-intending involves my intending to stir the ingredients (as my part in our preparing hollandaise sauce) and my believing both that you will pour the ingredients and that there is a mutual belief between us that you will pour and I will stir; and similarly for your we-intention.

Consider some central aspects of Tuomela and Miller's analysis (WI). First, a weintention has as its content "the full social action," $X(375)$-where the concept of joint action that figures in that content "is understood ... without reference to the notion of we-intention" (Tuomela 1990: 10). For Tuomela and Miller this conception of the content of a we-intention finds support in our ordinary attributions of intentions to participants in joint action since, they think, it captures the intuition that a participant in joint action will accept the locution "We will do $X$," rather than merely that of "I will do my part of $X$," as adequately describing his attitude. Second, clause (i) of (WI) captures the conative aspects of we-intending. By postulating that the we-intending agent "intends to do his part of $X$ as his part of $X$ " the authors mean that such an agent not only intends to do his part of $X$, but also has the "goal (purpose) that $X$ will be performed" (Tuomela and Miller 1988: 376; Tuomela 2005: 357). Thus, an agent's we-intention 
involves two conative elements: a firm commitment (intention) to doing his part in the joint activity, and a weaker commitment (goal) to the joint action's coming about. The former attempts to capture the intuition that the joint action will come about only if each participant does his part in it and that a robust commitment of each to doing his part is necessary to secure this. The latter is motivated by the idea that the absence of some type of commitment, however weak, to the joint action's coming about is incompatible with joint intention and action, as when a violinist intends to play his part in a symphony but nonetheless acts with the intention of ridiculing the visiting conductor and with no concern as to whether the joint performance comes about (Tuomela and Miller 1988: 376). Several questions arise here: What does support the cited asymmetry in commitment of an individual participant, to the joint action and to his part in it? Is an individual's commitment to the joint activity in shared intention better conceived of in terms of the notion of a goal than in terms of that of an intention? In particular, is an individual's goal that the joint action comes about a robust enough attitude to facilitate the interpersonal coordination characteristic of shared intention? For example, does it exert rational pressure on, and correspondingly dispose, such individual to eschew alternative options for action that are believed to be incompatible with the joint action's coming about? (Cf. Bratman's alternative conception below. On the general distinction between intention and goal, see esp. Bratman [1987] and Velleman [1997].) Third, clauses (ii) and (iii) of Tuomela and Miller's analysis of we-intention (WI) establish "cognitive presuppositions" on we-intending. Tuomela and Miller's idea is basically that in order for a participating agent to be able to form the intention in (i), he must have the beliefs cited in (ii) and (iii). Tuomela and Miller describe such beliefs as “conceptual preconditions" for we-intention (Tuomela and Miller 1988: 374, 377), but in later work Tuomela regards them as "minimal rationality conditions" for this attitude (2005: 329-30). 
This raises the question of whether Tuomela is here conflating too seemingly different issues: metaphysical (or conceptual) conditions for we-intention with normative (or rational) conditions for it.

Other reductive views in the spirit of Tuomela and Miller's have been offered as well. Seumas Miller (2001), for example, agrees that the conative profile of an individual who participates in a joint action $X$ includes his intending to do his part in $X$ and his having $X$ as his goal or -as he puts it-his "collective end". However, Miller sees the connection between such intention and end of an individual as being tighter than what Tuomela and Miller seem to assume. An individual intends to do his part of $X$, Miller asserts, "because" or "for the reason that" he has the joint action $X$ as his "collective end" (2001: 65, 73-74). Miller thinks that capturing this feature in a reductionist account of shared intention allows the latter to respond to several objections that have been levelled against it -including the objection immediately below. For other views in the spirit of Tuomela and Miller's, see Cohen and Levesque (1991) and Kutz (2000).

John Searle (1990) advances one of the most challenging objections to Tuomela and Miller's analysis of we-intention (WI). The challenge concentrates on their appeal to the notion of an individual's "doing his part" in the joint action that figures in such an analysis -although, it can generalize to other proposals for reduction. If we take this notion to mean, as the authors themselves suggest, "doing his part toward achieving the collective goal," Searle says, we will be introducing an element of circularity in the analysis, for we will have included the notion of weintention in the notion of "doing his part" (405. His emphasis). On the contrary, if we interpret the cited notion as not making reference to a collective goal, Searle argues, the analysis will be too weak. For there are cases that satisfy the conditions established for we-intentions (clauses (i)- 
(iii)) thus interpreted, but intuitively no genuine we-intention exists on the part of individuals (Searle 1990: 404-05). Either way, Searle concludes, Tuomela and Miller's analysis fails. (Tuomela's response in later work is to take the first horn of the proposed dilemma, stressing that his earlier account with Miller was not intended as a reductive account. See discussion in Chapter 3 above; see also Tuomela [2005: 355-61; 1995: 427-28, n6].)

Searle contends that we cannot analyze -as he interprets Tuomela and Miller (1988) attempt to do-an individual's we-intention in terms of, as he puts it, "I-intentions," that is, intentions expressible in the form "I intend to do such-and-such," even when such intentions are supplemented with beliefs about the other individuals' participation in the joint activity (1990, 404). The reason such reductive analyses fail, Searle contends, is that the notion of we-intention "implies the notion of cooperation" (1990: 406), whereas the notions of I-intention and of belief involved in the purported analyses need not. This leads Searle to propose instead a nonreductive view of the mental component of joint action and of "we-intention" in particular. According to Searle, a we-intention is a biologically primitive phenomenon in the mind of an individual that involves a commitment to cooperate with others to achieve a goal in a way that I-intentions plus relevant beliefs need not $(1990,406)$. We-intending, Searle maintains, is a "special" kind of intending (1990, 402), distinct from I-intending. We-intentions and I-intentions are thus in Searle's view intentions of different kinds (or "modes"). Searle's view involves several complexities and raises many interesting questions, which are not the object of discussion in this chapter (for discussion, see Chapter 3 above). But here it is worth mentioning a particular worry this view has given rise to. This is that not enough has been said to establish that we-intentions are indeed intentions of a kind different from ordinary I-intentions, and so, as Chris Kutz has put it, Searle's introduction of we-intention as a new item in our ontology of mental states "invites 
charges of proliferating intentional kinds, charges that methodological parsimony encourages us to try to avoid” (Kutz 2000: 3; see also Ludwig 2007a: 58, 61; Bratman 2014: 105-06).

Bratman proposes a reductive view of shared intention that attempts to give an answer to Searle's challenge that reductive views are either too weak or circular, but that also differs in many ways from Tuomela and Miller's view. To understand the main aspects of Bratman's view, it is imperative to locate it in relation to the author's "planning" theory of intention of an individual. According to Bratman's theory, individual (future-directed) intending or "planning" is at the heart of human agency, insofar as it plays some central characteristic roles in one's practical thought and action (1987). A distinctive role of intention, Bratman maintains, is to help organize and coordinate one's actions both over time and interpersonally. Intention plays this role in virtue of involving a two-fold commitment to action that other conative attitudes, such as desire, normally lack (15-18, 108-109). First, one's intending to do something involves a disposition to "settle" or "control" -rather than merely to "potentially influence"—what one is going to do: if one intends to perform an action, and one's intention persists until the time of action and nothing interferes, one will proceed to execute it then. Second, intending to perform an action disposes one to take the cited action as a fixed point in one's deliberations and to reason in certain ways. In particular, it disposes one to avoid reconsidering one's intention in the absence of new and significant information, to form further intentions about how to execute one's intended end, and to eschew from deliberation options believed to be incompatible with one's intention. It is one of Bratman's fundamental ideas that such dispositions to reasoning are responsive to or guided by, associated norms of intention rationality such as intention stability, means-end coherence of intentions, and intention consistency. 
Bratman contends that in parallel with individual intending, the mark of a group of individuals' shared intention to act together resides in the roles this latter phenomenon typically plays in such individuals' practical reasoning and action, in pursuit of their joint activity (Cf. Gold and Sugden [2007: 137] on the alternative claim that the mark of shared intention lies instead in the "mode" of practical reasoning, "team reasoning," by means of which the former is formed; see also Pacherie [2013]). Return to our shared intention to prepare hollandaise sauce together. According to Bratman, our shared intention to prepare hollandaise sauce will typically play three main interrelated roles. First, it will help us coordinate our individual actions: one of us will pour in the ingredients, for example, and the other will stir them. Second, our shared intention will help us coordinate our associated planning -for instance, if I plan to buy the ingredients but not to gather the necessary utensils, I will make sure that you plan to do the latter. Third, our shared intention will provide a background framework that can structure forms of bargaining and deliberation between us about how we will perform the joint activity -say, about what recipe we will follow, and so on. Bratman's idea is that our shared intention will typically play such trio of interrelated roles in ways that lead to our successfully making hollandaise sauce together. When an individual agent intends to perform an action, Bratman claims, she commits to future conduct in ways that help organize, coordinate, and unify her agency over time. Much in the same way, Bratman suggests, when we share an intention to act together we commit to future conduct in ways that help organize, coordinate, and unify our joint intentional agency (Bratman 1993: 112).

It is a key thesis of Bratman's theory that shared intention reduces to -or is realized bya complex structure of attitudes of individuals and that it is in virtue of this structure of attitudes that such phenomenon plays the aforementioned trio of roles. For Bratman this complex structure 
involves, mainly, (a) intentions of each individual in favor of the joint activity itself -where the latter is understood in a way that is neutral with respect to shared intentionality (see, also, Alonso 2009; Cf. Ludwig 2007b, 2017 and discussion below). When you and I share an intention to prepare hollandaise sauce together, I intend that we prepare the sauce and you intend that we prepare the sauce. In Bratman's view, an intention in favor of the joint activity is not, unlike Searle's we-intention, a special type of intention. It is, rather, an ordinary intention of an individual. Nor is it, in contrast to Tuomela and Miller's view (1988), an intention in favor of the joint activity only in name -i.e., one that reduces in the end to, among other things, an individual's intention to do his part in the joint activity and a goal of his that the joint action comes about. In Bratman's view, what an individual intends in shared intention is, strictly speaking, the joint activity itself. Furthermore, Bratman argues that in shared intention such intentions of individuals are interconnected in complex ways: inter alia, (b) such intentions are "reflexive" and "interlocking" (each intends that both his own intention and the intention of the other be effective); (c) they track the compatibility (or "meshing") of lower-level intentions (or "sub-plans") of each concerning ways of carrying out the joint activity; (d) they are based on the belief that the intention of each will persist so long as the other's intention persists as well -that is, that the intentions of each are "persistence interdependent" - and that if such intentions persist, they will lead to joint action; (e) they are, in fact, persistence interdependent; and (f) the cited structure of intentions (a)-(e) is common knowledge between the individuals (1993: 11720; 2014, Ch. 2-3).

But how does the cited structure of attitudes play the characteristic trio of roles of shared intention? Bratman's answer involves three basic steps. First, Bratman says, we start by noting that shared intention involves intentions of individuals, intentions with the cited special contents 
and interconnected in the aforementioned ways. Then, we note that these intentions are, after all, ordinary intentions of individuals, and as such, are subject to norms of intention rationality such as intention stability, means-end coherence, and intention consistency (Cf. Roth [2003] on the relevance of alternative norms of "practical intersubjectivity" for shared intention). Finally, Bratman concludes, we note that such norms of intention rationality exert pressure on those intentions of individuals -intentions with such contents and so interconnected - in ways that lead to the coordination of action and of planning, and to appropriate bargaining and deliberation, in pursuit of the joint activity (1993: 122-25; 2014, Ch. 4). Thus, we may read certain aspects of Bratman's view -mainly, his arguments in favor of conditions (a)-(f) being sufficient for shared intention and his appeal to a notion of intending the joint activity that is neutral with respect to shared intentionality - as providing an answer to Searle's challenge to reductive views mentioned above.

Bratman's planning theory is plausibly the most elaborate and comprehensive view of shared intention on offer. However, critics have raised several objections to it. One line of objection centers on Bratman's idea that an individual may intend a joint activity, that is, the activity of a group. Some have wondered whether appeal to this idea does not in the end bring in a criticizable form of circularity to the view (Petersson 2007; Cf. Kutz 2000). Others have argued that the cited idea is incoherent, since it violates one or another essential condition on intending. For some, the cited condition is that one may only intend one's own actions (Stoutland 1997, 2002; Roughley 2001. Cf. Baier 1970); for others, the condition is that one may only intend what one takes oneself to "settle" (Velleman 1997) or "control" (Baier 1997). (See also Schmid [2008]; Roth [2014]; For discussion of this condition as applied to intentions in general, see Alonso [forthcoming]). Yet, others have wondered how such intentions could ever be formed 
(Roth 2004: 373-80). If, as Bratman suggests, my intention is truly interdependent with yours, how can I (reasonably) form my intention before you have formed yours, and how can you (reasonably) form yours before I have formed mine? (Cf. Velleman's conceptualization of the interdependence of such intentions in terms of conditional intentions [1997].) Another line of objection holds that it is psychologically too demanding -and, therefore, unnecessary-to suppose that the attitudes of individuals in shared intention are characteristically interconnected in the complex ways Bratman describes (See esp., Miller 2001, Tollefsen 2005, Pacherie 2011, Butterfill 2012). Bratman responds to most of these objections in $(1997 ; 2014)$.

Questions about Bratman's theory still remain. Some, for example, have to do with Bratman's later conception $(1997,2014)$ of the structure of interrelated intentions above, (a)-(f), as being only sufficient -rather than necessary and sufficient, as originally suggested (1993) for shared intention. One question here is whether Bratman's identification of one -though, perhaps important—realization of shared intention among many is enough to support his claim to the "primacy of intention" for shared intention, that is, the claim that "intentions ... are at the heart of the coordination and organization" distinctive of this phenomenon (2014: 29). Another related question is whether Bratman's general planning theory of intention does not commit us to a view in which intentions of individuals -albeit, not necessarily intentions of individuals in favor of the joint activity itself-are in fact necessary for shared intention. As mentioned above, in Bratman's theory, an individual's intention plays distinctive roles in his practical thought and action, that is, roles that cannot be played by a combination of other attitudes of that individual including his relevant desires and beliefs (1987). But, then, how could shared intention play analogous distinctive roles in the individuals' thought and action in pursuit of a joint activity, according to Bratman's theory of intention, if it did not involve relevant intentions on the part of 
(at least some) of them? Finally, there is a question as to whether it is a limitation of Bratman's approach that it concentrates on attitudes and interrelations that are only sufficient for shared intention, in that this does not seem to offer a principled way of separating out attitudes and interrelations that are essential to this phenomenon from those that are contingently associated with it. For further recent discussion of Bratman's work, see Ludwig (2015), Pacherie (2015), Petersson (2015), Roth (2015), Smith (2015), and Bratman (2015).

Ludwig offers, and has recently elaborated on, an alternative reductive view of shared intention (2007b, 2017). Ludwig regards his own view as broadly in the spirit of Bratman's (2017: 231, 251). However, his methodological approach for investigating shared intention differs dramatically from Bratman's. Whereas Bratman's strategy is to theorize about shared intention by reference primarily to the functional roles that this phenomenon plays in the individuals' thought and action, Ludwig's strategy is to investigate it mainly by analyzing the logical form of the sentences we ordinarily use to express our thoughts about it -sentences such as "We intend to prepare hollandaise sauce". Ludwig thinks that_ordinary language not only represents the contours of the phenomenon of shared intention in a fairly accurate way but also captures what is distinctive about it (2017: 6-7).

Such conceptual analysis indicates, Ludwig maintains, that a group of individuals shares an intention to perform a joint action if and only if each individual in the group "we-intends" that the group perform such an action (2017: 191). But what does a we-intention amount to in Ludwig's view? Like Bratman, but unlike Searle, Ludwig thinks that "what is special about [weintention] is to be sought in its content rather than mode" (182). In Ludwig's view, for me to weintend that we prepare hollandaise sauce is for me to intend that we prepare hollandaise sauce in accordance with a "shared plan" -where this is, more precisely, for me to have "an intention 
whose content is that that very intention bring it about in accordance with a plan [I] associate[e] with [my] intention at the time of action (that is, with [my] intention-in-action) that [I am] the agent of an event which is our coming to [prepare hollandaise sauce] by way of a shared plan" (201). In this way, Ludwig explains, my we-intention that we prepare hollandaise sauce is an intention directed both at my doing my part in and at my contributing to our preparing hollandaise sauce together, in accordance with a shared plan (201). (Cf. Bratman's conception of the relevant intentions of individuals as directed solely at the joint activity and Tuomela and Miller's as involving both an intention directed at one's part in the joint activity and a goal directed at the joint activity itself.)

The idea that the joint action I we-intend be brought about in accordance with a shared plan is crucial to Ludwig's conception of we-intention. By "plan" Ludwig means basically a recipe for action, involving typically "a series of actions carried out in a particular order with the goal of thereby bringing about an event or state of affairs" (213). (Cf. Bratman's distinction between two uses of "plan," respectively, as a recipe or abstract procedure for achieving a goal, and as basically the mental state of intending [1987: 28-29]. While Bratman uses "plan" in the latter sense, Ludwig does it in the former.) In addition, Ludwig notes, the shared plan component that figures in the content of a we-intention is specifically for bringing the joint action about, and it includes an assignment of roles (however specified) pertinent to its implementation (2017: 201-02). Further, the cited plan is a shared plan, Ludwig explains, in that each individual in the group has basically the same plan for joint action -where sameness of plan admits of some discrepancy concerning specific details, usually about the other's part (214-15). (Thus, Ludwig's "shared plan" does not pick out the same phenomenon that our usual talk of "shared intention" does, namely, the intention of a group.) 
Ludwig sees the shared plan component of a we-intention as helping secure two features of joint intentional action. First, the existence of such a component in the content of a weintention excludes cases where the joint action is brought about, but not "in the right way" (214). Second, and relatedly, it captures an element of interpersonal coordination essential to joint intentional action. (See Ludwig's discussion of the parallel with Bratman's appeal to "meshing subplans" in the contents of intentions of individuals [250-54]). This has important consequences according to Ludwig. Once we acknowledge the relevance of the shared plan component of a we-intention, Ludwig claims, we realize that the condition of "openness" or mutual belief commonly attributed to shared intention and action is not essential to them. Nor, Ludwig adds, is the condition of believing that the others (will) intend likewise and/or do their parts essential to an individual's we-intention, either (194-97, 219-21). Imagine a context of high uncertainty and absence of communication between the members of a group. In such a context, Ludwig exemplifies, each member in the group may intend to do his part in a joint activity, and carry out that intention, in accordance to a pre-arranged shared plan, not believing but yet "hoping that there are still others who are doing their parts, however unlikely it may seem ... and so they [may act] together, according to their pre-arranged plan, and ... do so intentionally" (2017: 221. See also Ludwig 2007b, 387-88). Ludwig's rejection of such cognitive conditions on shared intention thus sets an important contrast with the aforementioned reductive views (and with many nonreductive views as well).

Ludwig's account (2017) is novel and complex, and deserves careful discussion. Here are two issues that invite further exploration. First, it might be insisted, Ludwig's claims notwithstanding, that shared intention necessarily involves some cognitive interdependence between the individuals' attitudes -usually in the form of (mutual) knowledge, beliefs, or 
assumptions about each other's intentions and the like. For one thing, it might be argued, such cognitive interdependence is what allows individuals to coordinate their thought and action in ways characteristic of shared intention, for it helps each of them to plan and act on the assumption that the others have the right attitudes and will perform the right actions when the time comes (Cf. Hobbs's [1990] critical remarks on Searle's [1990] view). Alternatively, it is not clear that each individual's merely intending that they act in accordance with what is in fact the same plan for joint action provides such a basis for coordination, independently of any cognitive stance such individuals may take with respect to each other's intentions. You and I may in fact each intend that we prepare hollandaise sauce in accordance with a plan for joint action and this turn out to be the same plan, but if none of us believes or assumes that such facts obtain, how can they serve as the relevant basis for coordination? Second, and relatedly, it might be wondered whether Ludwig's conception of shared intention does not involve a cognitive dimension after all. For Ludwig's talk of "hope" in the context of the aforementioned example leaves open the possibility that an individual's we-intention be necessarily framed by a cognitive attitude about the others' relevant attitudes, a cognitive attitude that need not be belief. (In relation to this, I have argued that cognitive attitudes subject to less stringent evidential standards, such as the attitude of reliance [2014, 2016a], might be better suited to play the role of cognitively framing the intentions of individuals in shared intention [2009, forthcoming]).

Some worries have been raised against reductive views of shared intention more broadly. Some have argued that neither shared intention in general nor intentions of individuals in particular are necessary to produce joint action, and instead that functionally more limited, and psychologically less demanding, structures of attitudes and relations ("shared goals") may do the relevant motivational work (Butterfill 2012; For discussion, see Blomberg 2014). Others, most 
notably Margaret Gilbert, have noted that shared intention is tightly connected to interpersonal obligations and practices of holding accountable, and have argued that reductive views cannot appropriately account for such connections (Gilbert 2000, 2009). For responses to these worries, see Bratman (2014) and Ludwig (2017). For attempts to combine socially-reducible psychological elements with elements of interpersonal normativity into an account of shared intention, see esp. Roth $(2004,2014)$ and Alonso (2009, 2016b).

There are interesting open questions for the aforementioned reductive views of shared intention. Views such as Tuomela and Miller's (1988) and Bratman's have focused mainly on cases of shared intention involving very few individual participants (typically two), and taking place in a context in which authority relations and significant differences in power between such individuals are absent. It is a vexed question what modifications those views will have to undergo, if any, to accommodate more complex cases of shared intention involving a large number of participants, authority relations, and so forth. For discussions of how an account in the spirit of Tuomela and Miller's view might be extended to cover complex cases, see, Kutz (2000) and Miller (2001). (Cf. Tuomela's extension of his own, later nonreductive view of shared intention [2007].) For discussion of the prospects for extending Bratman's view, see Shapiro (2014). Ludwig explores some of these issues in (2014). ${ }^{\mathrm{ii}}$

(5206 words)

\section{References}

Alonso, F. (2009) "Shared Intention, Reliance, and Interpersonal Obligations," Ethics 119: 444475. 
----- (2014) "What is reliance? Canadian Journal of Philosophy 44 (2014): 163-183.

----- (2016a) “Reasons for Reliance,” Ethics 126: 311-338.

---- (2016b) “A Dual Aspect Theory of Shared Intention,” Journal of Social Ontology 2: 271302.

---- (Forthcoming) “Intending, Settling, and Relying," in D. Shoemaker (ed.) Oxford Studies in Agency and Responsibility. Volume 4. New York: Oxford University Press.

Baier, A. (1970) “Act and Intent,” The Journal of Philosophy 67: 648-58.

---- (1997) "Doing things with Others: The Mental Commons," in L. Alanen, S. Heinämaa, and T. Wallgren (eds.) Commonality and Particularity in Ethics, New York: St. Martin's Press, Inc, pp. 15-44.

Blomberg, O. (2014) "Shared Goals and Development," Philosophical Quarterly 65:94-101.

----- (2016) "Common Knowledge and Reductionism about Shared Agency," Australasian Journal of Philosophy 94: 315-26.

Bratman, M. (1987) Intention, Plans, and Practical Reason. Cambridge: Harvard University Press.

---- (1993) "Shared Intention," reprinted in Faces of Intention. Cambridge: Cambridge University Press, 1999, pp 109-29.

----- (1997) "I Intend that We J," reprinted in Faces of Intention, pp.142-161.

----- (2006) "Dynamics of Sociality," Midwest Studies in Philosophy 30: 1-15.

---- (2009) "Modest Sociality and the Distinctiveness of Intention," Philosophical Studies 144:149-165.

----- (2014) Shared Agency: A Planning Theory of Acting Together. New York: Oxford University Press. 
----- (2015) "Shared Agency: Replies to Ludwig, Pacherie, Petersson, Roth, and Smith,” Journal of Social Ontology 1: 59-76.

Butterfill, S. (2012) “Joint Action and Development,” Philosophical Quarterly 62: 23-47.

Chant, S. R and Zachary E. (2008) "Epistemic Conditions for Collective Action," Mind 117: $549-573$.

Gilbert, M. (1992) On Social Facts. Princeton: Princeton University Press.

----- (2000) Sociality and Responsibility. Lanham, Md.: Rowman \& Littlefield.

----- (2009) “Shared Intention and Personal Intention.” Philosophical Studies 144:167-187.

Gold, N. and R. Sugden. (2007) "Collective Intentions and Team Agency," Journal of Philosophy 104: 109-137.

Hobbs, J. (2001) “Artificial Intelligence and Collective Intentionality: Comments on Searle and on Grosz and Sidner," in P. Cohen, J. Morgan, and M. Pollack (eds.) Intentions in Communication, Cambridge, Mass.: MIT Press, pp. 445-59.

Kutz, C. (2000) “Acting Together," Philosophy and Phenomenological Research 61:1-31.

Ludwig, K. (2007a) "Foundations of Social Reality in Collective Intentional Behavior," in S. L. Tsohatzidis (ed.) Intentional Acts and Institutional Facts, Dordrecht: Springer.

---- (2007b) “Collective Intentional Behavior from the Standpoint of Semantics," Noûs 41: 355393.

----- (2014) "Proxy Agency in Collective Action," Noûs 48: 75-105.

----- (2015) “Shared Agency in Modest Sociality,” Journal of Social Ontology 1: 7-15.

----- (2017) From Individual Agency to Plural Agency: Collective Action. Volume 1. New York: Oxford University Press.

Miller, S. (2001) Social Action: A Teleological Account. New York: Cambridge University Press. 
Pacherie, E. (2011) “Framing Joint Action," Review of Philosophy and Psychology 2: 173-92.

----- (2013) "Intentional Joint Agency: Shared Intention Lite," Synthese 190: 1817-1839.

----- (2015) "Modest Sociality: Continuities and Discontinuities," Journal of Social Ontology 1:

$17-26$.

Peterssen, B. (2007) “Collectivity and Circularity,” Journal of Philosophy 104: 138-156.

---- (2015) "Bratman, Searle, and Simplicity. A comment on Bratman, Shared Agency," Journal of Social Ontology 1: 27-37.

Roth, A. (2003) "Practical Intersubjectivity," in Frederick Schmitt (ed.) Socializing Metaphysics: the Nature of Social Reality, Lanham, MD: Rowman \& Littlefield, pp. 65-91.

----- (2004) "Shared Agency and Contralateral Commitments," Philosophical Review 113: 359410.

----- (2014) "Prediction, Authority, and Entitlement in Shared Activity," Noûs 48: 626-52.

---- (2015) "Practical Intersubjectivity and Normative Guidance: Bratman on Shared Agency," Journal of Social Ontology 1: 39-48.

Roughley, N. (2001) "Review of Bratrnan, Faces of Intention," International Journal of Philosophical Studies 9: 265-70.

Schmid, H. B. (2008) "Plural Action," Philosophy of the Social Sciences 38: 25-54.

Searle, J. (1990) "Collective Intentions and Actions," in P. Cohen, J. Morgan, and M. Pollack (eds.) Intentions in Communication, Cambridge, Mass.: MIT Press, pp. 401-15.

Shapiro, S. (2014) "Massively Shared Agency," in M. Vargas and G. Yaffe (eds.) Rational and Social Agency: Essays on The Philosophy of Michael Bratman,. New York: Oxford University Press, pp. 257-93. 
Smith, T. H. (2015) "Shared Agency on Gilbert and Deep Continuity," Journal of Social Ontology 1: 49-57.

Stoutland, F. (1997) "Why are Philosophers of Action so Anti-Social?" in L. Alanen, S. Heinämaa, and T. Wallgren (eds.) Commonality and Particularity in Ethics, New York: St. Martin's Press, pp. 45-74.

----- (2002) “Critical Notice of Michael Bratman's Faces of Intention," Philosophy and Phenomenological Research 65: 238-41.

Tollefsen, D. (2005) "Let's Pretend! Joint Action and Young Children," Philosophy of the Social Sciences 35: 75-97.

Tuomela, R. (1990) "What are Goals and Joint Goals," Theory and Decision 28: 1-20.

----- (1995) The Importance of Us. Palo Alto, CA: Stanford University Press.

----- (2005) “We-Intentions Revisited,” Philosophical Studies 125: 327-69.

----- (2007) The Philosophy of Sociality: The Shared Point of View. Oxford: Oxford University Press.

Tuomela, R. and K. Miller. (1988) “We-intentions,” Philosophical Studies 63: 367-89.

Biographical Note: Facundo M. Alonso is Assistant Professor of Philosophy at Miami University, Ohio. He works on issues in the philosophy of action and mind, normative ethics, and epistemology.

Related Topics: Collective Action and Agency (Ch. 2), Non-reductive views of Shared Intention (Ch.3), Interpersonal Obligations in Joint Action (Ch. 5), Proxy Agency in Collective Action (Ch. 6), Psychology of Joint Action (Ch. 7), Joint Commitment (Ch. 11), Common Knowledge 
(Ch. 15), Team Reasoning (Ch. 18).

${ }^{\text {i }}$ Partly due to criticisms by John Searle (1990), Tuomela and Miller's account has been interpreted by many as a conceptually reductive account. Although Tuomela has since denied that it was so intended (see, e.g., note 9 of Chapter 3, this volume), their account, thus interpreted, has had an enormous influence in the literature. For this reason, among others, I believe it is appropriate in this chapter to consider what their account exactly amounts to, and what problems it faces, when so construed. Henceforth, I will here treat Tuomela and Miller's account as a reductive account.

ii Thanks to Olle Blomberg, Michael Bratman, and Kirk Ludwig for valuable comments and suggestions on earlier drafts. 